\title{
Similarity versus liking as determinants of interpersonal attractiveness'
}

\author{
ELLIOT ARONSON AND PHILIP WORCHEL \\ UNIVERSITY OF TEXAS
}

In $a 2$ by 2 design, Ss were led to believe that a person with whom they had interacted either liked them or disliked them and that his attitudes on several issues were either similar or dissimilar to the S's own attitudes. The results indicated that "liking" had a significant effect upon the S's feelings for the other person - regardless of attitude similarity or dissimilarity. The results were discussed in terms of a possible alternative explanation for the bulk of the data showing a positive relationship between attitude similarity and interpersonal attraction.

Several recent experiments, notably by Byrne and his co-workers, have demonstrated that interpersonal attractiveness is a positive function of attitude similarity (e.g., Byrne, 1961, 1962; Byrne \& Wong, 1962; Byrne \& Nelson, 1965; Byrne \& Rhamey, 1965). Byrne has interpreted this relationship in terms of a reward theory of interpersonal attraction; i.e., people who share our attitudes reward us by providing us with consensual validation (Byrne, 1961). Although there is no denying the strength and ubiquitousness of the relationship between attitude similarity and attractiveness, it is conceivable that this relationship may be due, at least in part, to an implicit assumption that people who hold attitudes similar to our own will like us. In the vast majority of these experiments the only data the $S$ knows about the other person are his attitudes on a set of issues. There is no contact between the $S$ and the other person. It seems reasonable to conjecture that a $S(P)$ whose attitudes were similar to the other $(\mathrm{O})$ would assume that if he were to meet $O$, $O$ would tend to like him. There is ample evidence to show that individuals like those who seem to like them (e.g., Backman \& Secord, 1959; Aronson \& Linder, 1965). Consequently, it would seem essential to bring $P$ and $O$ into face-toface contact and examine the effects of $O^{\prime} s$ liking for $P$ and the similarity of $O^{\prime}$ 's and $P^{\prime} s$ attitudes as determinants of $\mathrm{P}^{\prime} \mathrm{S}$ liking for $\mathrm{O}-$ all in the context of the same experimental design. It is our prediction that, after a face-to-face interaction, if $O$ likes $P, P$ will like $O$; the similarity or dissimilarity of $O^{\prime}$ 's attitudes to $P^{\prime} s$ attitudes will have a negligible effect.

\section{Procedure}

The Ss consisted of 40 male undergraduate students who elected to serve in the experiment in partial fulfillment of the course requirement in introductory psychology at the University of Texas. Each S was informed that the study was concerned with decision-making and, for this purpose, he would be paired with a student from another introductory class in order to minimize the possibility of each being acquainted with the other. In actuality, the second student was a confederate whose behavior was preprogrammed by the experimenter.

At each experimental session it was arranged that the confederate enter the room a few minutes after the $S$ to avoid causing suspicion as to the confederate's actual role. The experimenter then administered, to both of them, the seven items of the Survey of Attitude Scale (Byrne, 1961). These items were used in order to make our situation as close as possible to the procedure employed by Byrne and his co-workers. The experimenter, the $\mathrm{S}$, and the confederate then engaged in a three-way conversation in which first the $S$ and then the confederate were asked to state the reasons for their responses. The confederate's responses were prearranged to provide attitude similarity or dissimilarity. In the Similarity condition the confederate agreed with the $\mathrm{S}$ on five of the seven items. In the Dissimilarity condition the confederate disagreed with the Sby at least three scale units on five items. Following this interaction, the $\mathrm{S}$ and the confederate were requested to write a few sentences regarding their reactions to the experiment. They were then instructed as follows: "The concluding part of this experiment is concerned with making decisions about another person on the basis of limited information. Now that you have had a chance to interact and to exhange some opinions, you have some information about each other. Your written comments about the experiment will also be exchanged as a source of additional information. Now, on the basis of the available information, you are asked to make some decisions about the other person. Try to predict the best you can how the other person would react in various circumstances."

The reactions to the experiment written by the confederate were designed to provide different combinations of liking and similarity as follows:

Similar
Like

This has been a fairly interesting experiment. We agreed on many things. I enjoyed working with him in the experiment; he seems like a really profound and interesting person, wellinformed.

Dissimilar

This has been a fairly interesting experiment. Although we disagreed on most things, I enjoyed working with him in the experiment. He seems like a really profound and interesting person, well-informed.
Dislike

This has been a fairly interesting experiment. Although we agreed on many things, I did not enjoy working with him in the experiment: he seems like a really shallow and uninteresting person, not well informed.
The "similarity" statement was attributed to the individual who had already expressed opinions similar to the S's; the "dissimilarity" statement was attributed to the individual who had already expressed attitudes dissimilar to the S's. These statements were used to further clarify and strengthen the similarity-dissimilarity manipulation.

Following the estimations of how the other $S$ would react in various circumstances, the Ss were asked to rate each other on the Interpersonal Attraction Scale (Byrne, 1961). The two items that were used as a measure of attraction were concerned with their ratings of (1) how much the $S$ would enjoy working with the other as a partner in another experiment, and (2) how much he liked the other person.

At the close of the experiment the experimenter provided the $S$ with a complete explanation of the experiment and discussed the reasons why deception was necessary. 
Table 1. Rated Attractiveness of Confederate as a Function of Attitude Similarity and Expressed Liking for the Subject

\begin{tabular}{ccc} 
& Like & Dislike \\
\hline Similar & 12.9 & 9.5 \\
Dissimilar & 12.1 & 8.1 \\
\hline
\end{tabular}

\section{Results and Discussion}

Since the responses to the two measures of liking were virtually identical, they were combined for purposes of analysis. The results are summarized in Table 1. The data were analyzed by analysis of variance. The results indicate a significant main effect due to liking $(p<.01)$. Neither the effect of similarity nor the interaction approaches significance. Thus, if the confederate indicated that he liked the $\mathrm{S}$, the $\mathrm{S}$ found the confederate attractive whether or not their attitudes were similar. If the confederate did not like the $S$, the $S$ considered him relatively unattractive even when they had similar attitudes. These results suggest the possibility that in earlier experiments on similarity of attitudes, Ss may have assumed that a person with highly similar attitudes would be favorably disposed toward them. When faced with clear evidence that the other person is not favorably disposed toward them, similarity of attitudes becomes inconsequential. Our data also suggest that under certain conditions, individuals can tolerate and even like people of diverse opinions and attitudes.

The results of this experiment are somewhat different from those obtained in an experimentby Byrne \& Rhamey (1965). These authors not only found a significant main effect due to $O^{\prime}$ 's liking for $P$, they also found a significant main effect due to the similarity of $O$ 's and P's attitudes. There is one major difference between the present experiment and the Byrne-Rhamey experiment. In the present experiment $P$ and $O$ have a face-to-face social encounter, whereas in the Byrne-Rhamey experiment they never met. Rather, each $S$ was told that another student had evaluated him (positively or negatively) as a function of having read S's previously stated attitudes on a number of issues. Theoretically, Byrne and Rhamey treat these evaluations as just another attitude-albeit a very important one. According to Byrne and Rhamey, if $O$ evaluates $P$ positively, he is displaying similarity on another attitude (since, presumably, $P$ likes himself); likewise, if $O$ evaluates $P$ negatively, he is displaying dissimilarity. We agree with the Byrne-Rhamey analysis, but we feel that it may be limited to a non-interactive situation. Because $O$ has never met $P, P$ probably would not regard this evaluation as ego-enhancing or ego-threatening since $O$ is evaluating $\mathbf{P}$ solely on the basis of examination of $\mathbf{P}^{\prime} \mathbf{s}$ written attitudes. It seems unlikely that $P$ would take this as a personal evaluation; rather, it may appear to be merely a statement of how important these attitudes are to $O$. Treated this way, $O^{\prime}$ 's evaluation of $P$ is, indeed, nothing more than an attitude about a specific set of attitudes. On the other hand, a face-to-face encounter presents a more impactful situation in which there are many stylistic and personality cues which $P$ expresses and which $O$ may appear to be responding to. Concequently, P should feel more elated by a positive evaluation or more depressed by a negative evaluation-because he knows that it is more than an evaluation of his attitudes.

At the same time it should be noted that, in the present experiment, although there is not a significant effect due to similarity, there is a slight tendency for the similar $O$ to be liked better than the dissimilar $O$. Consequently, it is conceivable that by increasing the number of attitude items, this effect could be strengthened-even in a face-to-face situation.

\section{References}

Aronson, E., \& Linder, D. E. Gain and loss of esteem as determinants of interpersonal attractiveness. J. exp. soc. Psychol., $1965,1,156-171$.

Backman, C. W., \& Secord, P. F. The effect of perceived liking on interpersonal attraction. Hum. Relat., 1959, 12, 379-384.

Byrne, D. Interpersonal attraction and attitude similarity. J. $a b$ norm. soc. Psychol., 1961, 62, 713-715.

Byrme, D. Response to attitude similarity-dissimilarity as a function of affiliation need. J. Pers., 1962, 30, 164-177.

Byme, D., \& Nelson, D. Attraction as a linear function of proportion of positive reinforcements. J. pers. soc. Psychol., 1965 , 1, 659-663

Byme, D., \& Rhamey, R. Magnitude of positive and negative reinforcements as a determinant of attraction. J.pers. soc. Psychol., $1965,2,884-889$.

Byrne, D., \& Wong, T. J. Racial prejudice, interpersonal attraction, and assumed dissimilarity of attitudes. J.abnorm. soc. Psychol., $1962,65,246-253$.

\section{Note}

1. Work on this project was sponsored jointly by NSF Grant GS 750 to Elliot Aronson and Nonr Grant 375(19) to Philip Worchel. We wish to thank Mr. Lawrence McCarron and Mr. Richard Mc'Whirter for their help in this experiment. 